\title{
P02-04. Multimeric soluble CD40 ligand efficiently enhances HIV specific cellular immune responses during DNA prime and boost with attenuated poxvirus strains J Najera*, C Gomez and M Esteban
}

Address: Molecular and Cellular Biology, Centro Nacional de Biotecnología-CSIC, Madrid, Spain

* Corresponding author

from AIDS Vaccine 2009

Paris, France. 19-22 October 2009

Published: 22 October 2009

Retrovirology 2009, 6(Suppl 3):P9 doi:10.1 I86/I 742-4690-6-S3-P9

This abstract is available from: http://www.retrovirology.com/content/6/S3/P9

(C) 2009 Najera et al; licensee BioMed Central Ltd.

\section{Background}

The attenuated poxvirus vectors MVA and NYVAC are now in clinical trials against HIV/AIDS. Due to the vectors restricted replication capacity in human cells, approaches to enhance their immunogenicity are highly desirable.

\section{Methods}

Here, we have analyzed the ability of a soluble form of hexameric CD40L (sCD40L) to stimulate specific immune responses to HIV antigens when inoculated in mice during priming with DNA and in the booster with MVA or NYVAC, expressing the vectors HIV-1 Env, Gag, Pol and Nef antigens from clade $B$.

\section{Results}

Our findings revealed that SCD40L in DNA/poxvirus combination enhanced the magnitude about 2-fold (DNA-B/ MVA-B) and 4-fold (DNA-B/NYVAC-B), as well as the breath of the HIV antigen specific cellular immune responses. SCD40L was necessary in both prime and boost inoculations triggering a potent polarization of the the response towards a Th1 type. In DNA-B/NYVAC-B regime the addition of $\mathrm{sCD} 40 \mathrm{~L}$ significantly enhanced the humoral immune response against HIV gp160, but not in DNA-B/MVA-B combination.

\section{Conclusion}

These findings provided evidence for the immunostimulatory benefit od sCD40L when DNA and the poxvirus vectors MVA and NYVAC are used as immunogens. 